\title{
THE EFFECT OF INJECTABLE VITAMIN E AND TRACE MINERALS (SELENIUM, CALCIUM, PHOSPHATE, COPPER, AND COBALT) ON REPRODUCTIVE PERFORMANCE DURING NON-BREEDING SEASON IN AWASSI EWES
}

\section{A.K. ZONTURLU1, C. KACAR ${ }^{2}$, M. SÖNMEZ ${ }^{3}$, A. YUCE ${ }^{4}$, S. KAYA ${ }^{2}$}

\author{
${ }^{1}$ Department of Obstetrics and Gynaecology, Faculty of Veterinary Medicine, Harran University, 63300, Şanliurfa, \\ Turkey; \\ ${ }^{2}$ Department of Obstetrics and Gynaecology, Faculty of Veterinary Medicine, Kafkas University, 36000, Kars, Turkey, \\ e-mail cihan3000@hotmail.com (corresponding author); \\ ${ }^{3}$ Department of Reproduction and Artificial Insemination, Faculty of Veterinary Medicine, Firat University, 23119, \\ Elazig, Turkey; \\ ${ }^{4}$ Department of Physiology, Faculty of Veterinary Medicine, Furat University, 23119, Elazig, Turkey \\ The authors declare no conflict of interests \\ Received December 30, 2016
}

Abstract

Progesterone in combination with pregnant mare serum gonadotropin (PMSG) is widely used to synchronize estrus in ewes. It is also known that various minerals and vitamins are necessary to provide animal reproductive health, and their blood level is reliably associated with reproductive performance. The objective of our research was to determine the effects of supplementation of vitamin $\mathrm{E}$ and mineral mixtures during progesterone treatment on reproductive performance of estrus-induced ewes during the non-breeding season. The present study was carried out between May and June, which is the period accepted as non-breeding season for ewes in Sanliurfa province of Southeast Turkey. A total of 148 non-lactating adult ewes of Awassi breeds in good body score condition, ranging in age from 2 to 4 years and weighting between 45 and $60 \mathrm{~kg}$ were used in this study. Estrus was synchronized in all ewes using the intravaginal sponges containing $20 \mathrm{mg}$ fluorogestone acetate. The intravaginal sponges were inserted into vagina of each ewe for 14 days. At the time of sponge withdrawal (day 0), all ewes were injected intramuscularly with 10 $\mathrm{IU} / \mathrm{kg}$ of PMSG for stimulation of estrus and ovulation. Treatment group $(n=74)$ received orally supplementation of vitamin $\mathrm{E}$ and mineral mixtures (Bakose ${ }^{\circledR}$ capsule; Ceva Dif, Istanbul, Turkey; a capsule contains $500 \mathrm{IU}$ vitamin E acetate, $2.5 \mathrm{mg}$ sodium selenite, $150 \mathrm{mg}$ dicalcium phosphate, $10 \mathrm{mg}$ copper sulphate, $12.5 \mathrm{mg}$ cobalt sulphate) at the four times a week apart during progestagen treatment and at the time mated. The remaining ewes $(n=74)$ served as control group, and the each female in this group also received only placebo instead of vitamin and mineral supplementation. They were tested for pregnancy detection on day 40 after mating using real time ultrasonography with 5-7.5 MHz linear array rectal transducer. The estrus response was $87.8 \%$ and $82.4 \%$ for the treatment and control groups, respectively. The overall pregnancy rate was $71.4 \%(90 / 126)$. The gestation length was similar between groups and it averaged 149.4 \pm 0.3 days. The lambing rate was $75.4 \%$ $(49 / 65)$ and $65.6 \%(40 / 61)$ for the treatment and control groups, respectively. The number of multiple births $(42.9 \%$ versus $20.0 \%)$ and prolificacy rate were higher $(\mathrm{P}<0.05)$ for the treatment group than those of control group. It is concluded that vitamin $\mathrm{E}$ and the multi-trace minerals/bolus given to Awassi ewes 14 days before mating significantly increased the proficiency rate, the multiple births rates and led to stronger manifested estrus behaviors.

Keywords: ewes, progesterone, pregnant mare serum gonadotropin, PMSG, vitamin E, trace minerals, reproductive performance

The progesterone-PMSG based estrus synchronization protocols have been widely used in ewes, in especially, during non-breeding season [1-3]. The ultimate aims of any estrous synchronization method are to reduce the time used for estrous detection and, to provide acceptable pregnancy rates and high proficiency rate [4]. However, the long-term application of progesterone treatment has been associated with a lesser fertility [5].

In ewes, the ovarian follicle population is known to be rather sensitive to 
dietary intake, and it is reported that both folliculogenesis and ovulation can be increased through nutritional manipulations [6]. In the other hand, various minerals and vitamins are essential for reproductive health of animals.

There is a significant relationship between the plasma levels of these substances and reproductive performance. In especially, the deficiencies of some trace elements such as vitamin copper, cobalt and selenium, suppress the expression of estrus behaviors, reduces ovulatory, induce embryonic loss and fetal death [7, 8]. Zinc, copper and manganese levels are higher in the conceptus, when compared to other reproductive tissues, which shows that the conceptus accumulates these minerals for its development, growth and vitality [7]. Vitamin E plays an important role in the management of oxidative stress. Oxidative stress adversely affects both ovarian activity and follicular development [9].

The objective was to determine the effects of supplementation of vitamin $\mathrm{E}$ and mineral mixtures during progesterone treatment on reproductive performance of estrus-induced ewes during in the non-breeding season.

Technique. The present study was carried out between May and June, which is the period accepted as non-breeding season for ewes in Sanliurfa province of Southeast Turkey located at latitude of $3710^{\prime} \mathrm{N}$, at longitude of $3903^{\prime} \mathrm{E}$ and at altitude of $518 \mathrm{~m}$ above sea level.

A total of 148 non-lactating adult ewes of Awassi breeds in good body score condition, ranging in age from 2 to 4 years and weighting between 45 and $60 \mathrm{~kg}$ were used in this study. In addition, twelve Awassi breeding rams of proved fertility were used in the present study. All females were isolated from rams at least 4 weeks until the start of the experiment period. They were housed together in a commercial farm in Sanliurfa province. They were allowed to mixed graze at pasture of the farm throughout the day, and were kept indoors at night. When the ewes were kept indoors, they were given a diet composed of $0.5 \mathrm{~kg}$ of concentrate and $0.5 \mathrm{~kg}$ of alfalfa hay per animal per day during the experimental period. The fresh drinking water was available ad libitum. All procedures were conducted in compliance with National Animal Care and Use Committee guidelines.

At the beginning of the study, the females were divided at random into two equal groups according to age and body weight. Hormonal treatments for induction of estrus were the same in both groups. Estrus was synchronized in all ewes using the intravaginal sponges containing $20 \mathrm{mg}$ fluorogestone acetate (Chrono-gest ${ }^{\circledR}$; Intervet, Istanbul, Turkey). The intravaginal sponges were inserted into vagina of each ewe for 14 days. At the time of sponge withdrawal (day 0), all ewes were injected intramuscularly with $10 \mathrm{IU} / \mathrm{kg}$ of PMSG for stimulation of estrus and ovulation. Treatment group $(n=74)$ received orally supplementation of vitamin and mineral mixtures (Bakosel ${ }^{\circledR}$ capsule; Ceva Dif, Istanbul, Turkey; a capsule contains $500 \mathrm{IU}$ vitamin E acetate, 2,5 mg sodium selenite, $150 \mathrm{mg}$ dicalcium phosphate, $10 \mathrm{mg}$ copper sulphate, $12.5 \mathrm{mg}$ cobalt sulphate) at the four times a week apart during progestagen treatment and at the time mated. The remaining ewes $(n=74)$ served as control group and, the each female in this group also received only placebo instead of vitamin and mineral supplementation.

Following the termination of progesterone treatment, all ewes were checked for behavioral signs of estrus for $30 \mathrm{~min}$ at $8 \mathrm{~h}$ intervals $(06: 00 \mathrm{~h}$, 14:00 $\mathrm{h}$ and $22: 00 \mathrm{~h}$ ) for a period of $96 \mathrm{~h}$ by visual observation using six rams equipped with an abdominal apron to avoid penetration. The onset of estrus was considered as the time the first permission to be mounted, and the interval from sponge removal to onset of estrus was recorded. Estrous duration was defined as the time elapsed between the first and last accepted mount within the same estrous 
period. The intensity of estrus was recorded as attractive ewes that had very strong behavioral signs or receptive ewes that had normal behavioral signs regarding to visibility, intensity and frequency of occurrence of the expression of estrus behaviors as searching for the male and remain very close to it, restlessness, bleating, frequent urination, vaginal discharge, hyperemia and oedema of vulva.

All females in estrus were hand-mated twice at 8 and $16 \mathrm{~h}$ after onset of estrus by a ram with known fertility. They were tested for pregnancy detection on day 40 after mating using real time ultrasonography (Falco Vet, Pie Data Medical, Maastricht, and the Netherlands) with $5-7.5 \mathrm{MHz}$ linear array rectal transducer. They were confirmed by the occurrence of parturition.

The following reproductive parameters were recorded; estrous response (number of ewes in estrus/number of treated ewes $\times 100$ ), interval to estrus (the time elapsed from sponge removal to onset of estrus), estrous duration (the time elapsed from first to last mounting acceptances), estrous intensity (attractive or receptive), pregnancy rate (number of pregnant ewes/number of mated ewes $\times 100$ ), gestation length (the time elapsed from breeding to lambing), lambing rate (number of ewes lambing/number of mated ewes $\times 100$ ) and prolificacy rate (number of lambs born alive/number of ewes lambing).

Data are presented as mean \pm SEM. The differences in the average interval from sponge removal to onset of estrus, estrous duration, gestation length and prolificacy rate were compared between control and treatment groups using the Student's $t$-test. The proportions of ewe in estrus, conception rate and kidding rate were analyzed using Chi-square test. Differences were considered significant at a level of $\mathrm{P}<0.05$. The SPSS/PC program (Version 10.0; SPSS, USA) was used for all analyses.

Results. Design of the experiment is visualized in the scheme (Fig.).

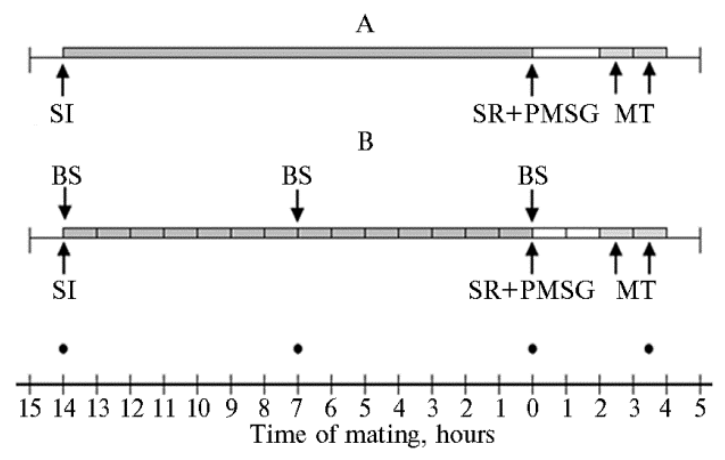

Schematic presentation of the experimental
design: SI - sponge insertion, SR - sponge
removal, MT - mating, BS and $\bullet-$ sup-
plementation of vitamin-mineral mixtures,
PMSG - injection of PMSG.

The reproductive responses in ewes synchronized for estrus using intravaginal sponges/PMSG and received supplementation of vitamin E and mineral mixtures (treatment group) or placebo (control group) during non-breeding season

are shown in Table 1.

The reproductive responses in ewes synchronized for estrus using intravaginal sponges/PMSG and received supplementation of vitamin E and mineral mixtures (treatment group) or placebo (control group) during non-breeding season are shown in the Table. The overall proportion of ewes exhibiting clinical signs of estrus was $85.1 \%(126 / 148)$. Nine ewes from treatment group and thirteen ewes from control group did not show any overt signs of estrus during the observation period. There was no significant difference $(P>0.05)$ in estrous response between the two treatments.

The average time elapsed from sponges removal to onset of estrus were $43.2 \pm 1.1 \mathrm{~h}$ and $45.3 \pm 1.0 \mathrm{~h}$ for the treatment and control groups, respectively. The mean estrous duration was $30.9 \pm 0.7 \mathrm{~h}$ for treatment animals and $27.3 \pm 0.6 \mathrm{~h}$ for control animals. No significant difference was observed between groups regarding the interval to estrus and estrous duration. However, the intensity of be- 
havioral signs of estrus was remarkably stronger $(\mathrm{P}<0.05)$ for treatment group than those of the control group.

The overall pregnancy rate was $71.4 \%$ (90/126). The gestation length was similar between groups and it averaged $149.4 \pm 0.3$ day. The lambing rate was $75.4 \%(49 / 65)$ and $65.6 \%(40 / 61)$ for the treatment and control groups, respectively. The prolificacy rate was $1.45 \pm 0.08(71 / 49)$ and $1.23 \pm 0.08(49 / 40)$ for the treatment and control group, respectively. No statistically significant differences were observed between groups in terms of conception rate and lambing rate. However, the number of multiple births $(42.9 \%$ versus $20.0 \%)$ and prolificacy rate were higher $(\mathrm{P}<0.05)$ for the treatment group than those of control group.

The reproductive responses (mean $\pm \mathrm{SEM}$ ) in ewes synchronized for estrus using intravaginal sponges/PMSG and received supplementation of vitamin $E$ and mineral mixtures (treatment group) or placebo (control group) during non-breeding season

\begin{tabular}{lccc}
\hline \multicolumn{1}{c}{ Reproductive parameters } & Control & Treatment & Total \\
\hline Estrus response, $\%$ & $82.4 \%(61 / 74)^{\mathrm{a}}$ & $87.8 \%(65 / 74)^{\mathrm{a}}$ & $85.1 \%(126 / 148)$ \\
Interval to estrus, hours & $45.3 \pm 1.0^{\mathrm{a}}$ & $43.2 \pm 1.1^{\mathrm{a}}$ & $44.2 \pm 0.7$ \\
Estrous duration, hours & $27.3 \pm 0.6^{\mathrm{a}}$ & $30.9 \pm 0.7^{\mathrm{a}}$ & $29.1 \pm 0.5$ \\
Estrous intensity & & & \\
$\quad$ attractive & $42.5 \%(32 / 61)^{\mathrm{a}}$ & $73.8 \%(48 / 65)^{\mathrm{b}}$ & $63.5 \%(80 / 126)$ \\
$\quad$ receptive & 61 & $26.2 \%(17 / 65)^{\mathrm{b}}$ & $36.5 \%(46 / 126)$ \\
Number of ewes mated & $67.2 \%(41 / 61)^{\mathrm{a}}$ & $75.4 \%(49 / 65)^{\mathrm{a}}$ & $71.4 \%(90 / 126)$ \\
Pregnancy rate & $65.6 \%(40 / 61)^{\mathrm{a}}$ & $75.4 \%(49 / 65)^{\mathrm{a}}$ & $70.6 \%(89 / 126)$ \\
Lambing rate & $148.9 \pm 0.4^{\mathrm{a}}$ & $149.7 \pm 0.3^{\mathrm{a}}$ & $149.4 \pm 0.3$ \\
Gestation period, days & 49 & 71 & 120 \\
The number of kids & $32(32)$ & $28(28)$ & $60(60)$ \\
$\quad$ including $\quad$ singleton & $7(14)$ & $20(40)$ & $27(54)$ \\
$\quad$ twin & $1(3)$ & $1(3)$ & $2(6)$ \\
$\quad$ triplet & $20.0 \%(8 / 40)^{\mathrm{a}}$ & $42.9 \%(21 / 49)^{\mathrm{b}}$ & $32.6 \%(29 / 89)$ \\
Multiple birth rates, $\%$ & $1.23 \pm 0.08(49 / 40)^{\mathrm{a}}$ & $1.45 \pm 0.08(71 / 49)^{\mathrm{b}}$ & $1.35 \pm 0.06(120 / 89)$ \\
Proficiency rate & Note. The values within a same line with different superscripts $(\mathrm{a}, \mathrm{b})$ are significantly different $(\mathrm{P}<0.05)$. \\
\hline
\end{tabular}

This study demonstrated the effects of vitamin $\mathrm{E}$ and multi-trace element (selenium, calcium, phosphate, copper and cobalt) injection on the reproductive performance of seasonally anoestrous Awassi sheep, which were treated with a progesterone- and PMSG-based estrus synchronization protocol.

In this study, $87.8 \%$ of ewes in the treatment group and $82.4 \%$ of ewes in the control group were detected in estrus during the observation period. The mean estrous response was $85.1 \%$. These results are similar to the findings of other researchers $[10,11]$. The ovarian sensitivity to hormonal manipulation may be different individually during anoestrous period.

An important requirement for successful estrous synchronization is uniformity of the time elapsed from the end of treatment to the onset of estrus. The overall average interval elapsed from sponge removal to onset of estrus was $44.2 \pm 0.7$ in this study (see Table). The interval obtained in this trial was comparable to the findings of M. Ali [12] and I. Dogan et al. [13], and was longer than the $38.8 \pm 1.6 \mathrm{~h}$ reported by $\mathrm{R}$. Ungerfeld et al. [14], but shorten than the $69.0 \pm 9.9 \mathrm{~h}$ reported by A. Ali [15]. It may be affected many exogenous factors such as nutrition, daylight, environmental factors, presence of male after sponge removal.

In our study, the estrous duration was similar between treatment and control groups, the mean estrous duration was $30.9 \pm 0.7 \mathrm{~h}$ for treatment and $27.3 \pm 0.6 \mathrm{~h}$ for untreatment groups and the overall estrous duration was $29.1 \pm 1.15 \mathrm{~h}$ in this study. M. Hashemi et al. [10] reported the ranges of duration of estrus period from 22 to $31 \mathrm{~h}$ using different progesterone treatments outside the natural breeding season in Karakul ewes. N. Ozyurtlu et al. [16], recorded as 29-30 $\mathrm{h}$ duration for induced estrous with various progestagens non-breeding 
season. These differences might be due to breed, nutrition, stress, location, and present of male. It was observed that the Vitamin E and multi-trace minerals treatment did not showed any significant advantage with respect to the estrous response, the average elapsed time from sponge removal to onset of estrus and the estrous duration in this study. This may be explained that almost all of the ewes had normal ovarian cyclic activity in breeding season.

M. Hidiroglou [17] reported that trace elements have a major role in reproductive performance and fertility parameters in sheep. It has been ascertained that the administration of multi-trace element and vitamin ruminal boluses to ewes, in advance of mating, significantly increased both the lambing and twin-lambing rates [18, 19]. On the other hand [20], Se and vitamin E supplementation did not increase the reproductive or rearing performance of 2and 3-year old ewes. Selenium is particularly significant for superovulation in cows as well as for sperm quality and multiple lambing in sheep, as it has a major role in sperm transport and the formation of ova [21]. The findings obtained in this study are similar to those previously reported [18] and demonstrate an increase in the multiple lambing rate of ewes supplemented with vitamin $\mathrm{E}$ and minerals in advance of mating.

Cobalt is a trace element required for the synthesis of vitamin $\mathrm{B}_{12}$. It has been determined that sheep with cobalt deficiency show higher rates of stillbirth and neonatal death and lower lambing rates [22]. Cobalt deficiency is also known to be associated with multiple ovulation, reduced conception rates and a decrease in the manifestation of clinical oestrus signs [17]. In this study, it was observed that the ewes included in the treatment group, which received vitamin E and minerals, displayed the clinical signs of oestrus more strongly, attracted a greater number of rams and did not try to escape the rams during mounting. It was observed that these ewes remained still and allowed the rams to mount. On the other hand, the ewes, which had not received vitamin E and trace elements, displayed irregular estrus are weaker compared to other ewes.

It is concluded that vitamin $\mathrm{E}$ the multi-trace minerals/bolus given to Awassi ewe before 14 days mating significantly increased the proficiency rate, the multiple births rates and stronger manifesto estrus behaviors.

\section{RE F E R E N CES}

1. Gungor O., Cenesiz M., Pancarc1 S.M., Yildiz S., Kaya M, Kacar C., Ozyurtlu N., Gurbulak K. Effects of different intravaginal progesterone releasing devices on estrous synchronization and LH surge in fat-tailed ewes during non-breeding season. Medycyna Weterynaryjna, 2007, 63(11): 1316-1319.

2. Karagiannidis A., Varsakeli S., Karatzas G., Brozos C. Effect of time of artificial insemination on fertility of progestagen and PMSG treated indigenous Greek ewes, during non-breeding season. Small Ruminant Res., 2001, 39: 67-71.

3. Z a razaga L.A., G a t i a M.C., Galle go- Ca lvo L., C e li I., Guz mán J.L. The timing of oestrus, the preovulatory LH surge and ovulation in Blanca Andaluza goats synchronised by intravaginal progestagen sponge treatment is modified by season but not by body condition score. Anim. Reprod. Sci., 2014, 146: 170-175 (doi: 10.1016/j.anireprosci.2014.02.012).

4. S c a ra muzzi R.J., D own ing J.A., C a mpbel1 B.K., Cognie Y. Control of fertility and fecundity of sheep by means of hormonal manipulation. Aust. J. Biol. Sci., 1988, 41(1): 37-45.

5. Vicoles C., Forsberg M., Banchero G., Rubianes E. Effect of long-term and short-term progestagen treatment on follicular development and pregnancy rate in cyclic ewes. Theriogenology, 2001, 55(4): 993-1004.

6. S c a ra muzzi R.J., Ca m pbe 11 B.K., Downing J.A., Kendall N.R., Khalid M., $\mathrm{Muñoz}-\mathrm{Gutiérrez} \mathrm{M.,} \mathrm{Anongnart} \mathrm{Som} \mathrm{chit.} \mathrm{A} \mathrm{review} \mathrm{of} \mathrm{the} \mathrm{effects} \mathrm{of}$ supplementary nutrition in the ewe on the concentrations of reproductive and metabolic hormones and the mechanisms that regulate folliculogenesis and ovulation rate. Reprod. Nutr. Dev., 2006, 46: 339-354 (doi: 10.1051/rnd:2006016). 
7. Hoste t l e r C.E., Ki n c a id R.L., M i ra n d o M.A. The role of essential trace elements in embryonic and fetal development in livestock. Vet. J., 2003, 166(2): 125-139.

8. Mitche 11 L.M., Robi n s o n J.J., W a t t R.G., M c Evoy T.G., A s h w o rt h C.J., R o o k e J.A., D w y e C.M. Effects of cobalt/vitamin $B_{12}$ status in ewes on ovum development and lamb viability at birth. Reproduction, Fertility and Development, 2007, 19(4): 553-562 (doi: 10.1071/RD07012).

9. Liu S., Masters D., Fergusonand M., Thompson A. Vitamin E status and reproduction in sheep: potential implications for Australian sheep production. Anim. Prod. Sci., 2014, 54(6): 694-714 (doi: 10.1071/AN13243).

10. Has he mi M., S a fdarian M., K a fi M. Estrous response to synchronization of estrus using different progesterone treatments outside the natural breeding season in ewes. Small Ruminant Res., 2006, 65: 279-283 (doi: 10.1016/j.smallrumres.2005.07.051).

11. De Nicolo G. Morris S.T., Kenyon P.R., Morel P.C.H., Parkinson T.J. Melatonin-improved reproductive performance in sheep bred out of season. Anim. Reprod. Sci., 2008, 109(1-4): 124-133 (doi: 10.1016/j.anireprosci.2007.10.012).

12. Ali M. Relevance of type of breeding and single versus double sponge combined with PMSG on Herri ewes estrus exhibition and pregnancy rate. Global Veterinaria, 2014, 13(2): 166-172.

13. D o g a n I., N u r Z. Different estrous induction methods during the non-breeding season in Kivircik ewes. Veterinarni Medicina, 2006, 51(4): 133-138.

14. Unge rfe ld R., Rubi a n e s E. Short term primings with different progestogen intravaginal devices (MAP, FGA and CIDR) for eCG-estrous induction in anestrus ewes. Small Ruminant Res., 2002, 46(1): 63-66.

15. Ali A. Effect of time of eCG administration on follicular response and reproductive performance of FGA-treated Ossimi ewes. Small Ruminant Res., 2007, 72: 33-37.

16. Ozyurtu N., Kucukaslan I., Cetin Y. Characterization of oestrous induction response, oestrous duration, fecundity and fertility in Awassi ewes during the non-breeding season utilizing both CIDR and intravaginal sponge treatments. Reprod. Domest. Anim., 2010, 45: 464-467 (doi: 10.1111/j.1439-0531.2008.01246.x).

17. Hidiroglou M. Trace element deficiencies and fertility in ruminants: a review. J. Dairy Sci., 1979, 62(8): 1195-1206 (doi: 10.3168/jds.S0022-0302(79)83400-1).

18. He mingway R.G., Parkins J.J., Ritchie N.S. Enhanced reproductive performance of ewes given a sustained-release multi-trace element/vitamin ruminal bolus. Small Ruminant Res., 2001, 39(1): 25-30 (doi: 10.1016/S0921-4488(00)00175-9).

19. Abdollahi E., Kohram H., Shahir M.H., N e mati M.H. Effects of a sustained-release multi-trace element ruminal bolus on sex ratio, reproductive traits and lambs growth in synchronized Afshari ewes. Iranian Journal of Veterinary Science and Technology, 2015, 7: 1-11.

20. G a b rys z u k M., K lew i e J. Effect of injecting 2- and 3-year-old ewes with selenium and selenium-vitamin E on reproduction and rearing of lambs. Small Ruminant Res., 2002, 43(2): 127-132 (doi: 10.1016/S0921-4488(02)00005-6).

21. H e m i n g w a y R.G. The influences of dietary intakes and supplementation with selenium and vitamin $\mathrm{E}$ on reproduction diseases and reproductive efficiency in cattle and sheep. Vet. Res. Commun., 2003, 27(2): 159-174.

22. Fishe $\mathrm{r}$ G.E. Effect of cobalt deficiency in the pregnant ewe on reproductive performance and lamb viability. Res. Vet. Sci., 1991, 50(3): 319-327 (doi: 10.1016/0034-5288(91)90132-8). 